\section{Ações de saúde mental no Programa Saúde da Família: confluências e dissonâncias das práticas com os princípios das reformas psiquiátrica e sanitária}

\author{
Mental health care in the Family Health Program: \\ consensus and dissent in practices and principles \\ under the psychiatric reform and health \\ reform in Brazil
}

\author{
Mônica Nunes 1 \\ Vládia Jamile Jucá 1 \\ Carla Pedra Branca Valentim 1
}

\section{${ }^{1}$ Instituto de Saúde Coletiva, Universidade Federal da Bahia, Salvador, Bahia M. Nunes \\ Núcleo Interdisciplinar de Saúde Mental, Instituto de Saúde Coletiva, Universidade Federal da Bahia. Rua Basílio da Gama s/n, Campus Universitário do Canela, Salvador, BA 40110-140, Brasil. nunesm@ufba.br}

\begin{abstract}
In many psychiatric reforms based on the principles of deinstitutionalization of psychiatric patients and the consolidation of territorial systems for mental health care, the emphasis is on a mental health care system that includes the primary care network. In Brazil, the Psychiatric Reform emerged within the country's overall Health Reform, with which it shares common principles for reorienting the model of care. The current article discusses the links between these two movements through actual mental health care practices within the Family Health Program (FHP), based on an ethnographic study with four family health teams, in which the authors prioritize health workers' narratives. The article analyzes these practices, the discrepancies between guidelines and practice, obstacles and advances in the operationalization of activities, and limits to the comparison and potentialities for crosscutting application of particular epistemological fields like expanded clinical mental health practice and the FHP. The discussion is based on such concepts as the psychosocial care model, comprehensive care, social participation, territoriality, and collective actions.
\end{abstract}

Mental Health; Family Health Program; Primary Health Care

\section{Introdução}

Em vários paises do mundo, nas Reformas Psiquiátricas que se sedimentam sobre os pressupostos da desinstitucionalização dos pacientes psiquiátricos e da consolidação de bases territoriais do cuidado em saúde mental, a ênfase é atribuída a uma rede de cuidados que contemple a atenção básica, ou primária. Parte-se da premissa de que um grande número de problemas em saúde mental pode ser resolvido nesse nível de assistência, sem ter necessidade de serem referidos a níveis especializados do sistema de saúde 1. Enfatizase ainda a importância do desenvolvimento de ações de tipo preventivo e promocional da saúde mental que teriam, na atenção básica, o lócus preferencial de desenvolvimento.

Já nos anos de 1970 e 1980, a Organização Mundial da Saúde (OMS) 2 reconhece a magnitude dos problemas de saúde mental e admite a impossibilidade do seu cuidado ficar a cargo exclusivo de especialistas. Preconiza então a descentralização dos serviços existentes, a integração de serviços psiquiátricos em unidades de cuidados gerais, a formação de cuidadores não especializados e o aumento da participação da comunidade 3 .

No Brasil, essas idéias passam a ser incorporadas e veiculadas pelo movimento da Reforma Psiquiátrica Brasileira, que nasceu no bojo da Reforma Sanitária, tendo guardado consigo princípios e diretrizes que orientam esta última, 
em especial a universalidade, integralidade, descentralização e participação popular. Ao longo do seu desenvolvimento, que segue um curso particular e nem sempre coincidente com aquele da Reforma Sanitária, esforços foram mais ou menos dirigidos na perspectiva de recuperar esse sentido original, sobretudo no que tange à constituição de uma rede integrada de assistência ao portador de transtorno mental.

A despeito da Política de Saúde Mental, que norteia atualmente a Reforma Psiquiátrica, estimular práticas pautadas no território e articuladas em uma rede ampliada de serviços de saúde, a lacuna ainda parece ser grande entre o que essas diretrizes propõem e o que se observa na realidade concreta. Ademais, as concepções e práticas em saúde mental por ventura existentes no nível básico de atenção à saúde nem sempre condizem com o esperado por parte dos que formulam a Reforma Psiquiátrica Brasileira, gerando por vezes questionamentos quanto à sua real contribuição no sentido de avançar na reinserção social do portador de transtornos mentais e na desestigmatização e cuidado efetivo dessas pessoas.

Apesar do debate lançado, dados que permitam conhecer o nível de implementação de ações de saúde mental na rede básica ainda são muito incipientes. Buscando contribuir para a redução dessa lacuna, o presente estudo investigou a atuação de quatro equipes de saúde da família, situadas na cidade de Salvador, Bahia, no intuito de compreender como os profissionais de saúde interpretam o sofrimento mental e, para reduzilo, planejam e desenvolvem suas intervenções no contexto do Programa Saúde da Família (PSF). A investigação buscou ainda identificar ainda fatores favorecedores e dificultadores dessas ações, o nível de formação específica desses profissionais na área de saúde mental, o conhecimento que eles detinham acerca das propostas da Reforma Psiquiátrica e o nível de implantação e de funcionamento de uma rede de serviços que contemplasse ações em saúde mental.

Para tal investigação, partiremos, no tópico subseqüente, dos princípios normativos que orientam a Reforma Psiquiátrica e seu nível de confluência com a saúde mental no nível da atenção básica.

\section{A saúde mental na rede de atenção básica de saúde: convergências de princípios}

A configuração das práticas em saúde mental da Reforma Psiquiátrica orienta-se com base em fundamentos epistemológicos que se situam em ruptura ao paradigma médico-naturalista clássico ${ }^{4}$, atribuindo um novo lugar social para a loucura e, para isso, instaurando um Modelo Psicossocial de Cuidado ${ }^{5}$. Para Costa-Rosa 5 , esse novo modelo deve situar-se em contradição com o modelo antigo, asilar, em quatro parâmetros principais: na definição de "seu objeto" e dos "meios" teórico-técnicos de intervenção, nas formas da organização dos dispositivos institucionais, nas modalidades do relacionamento com os usuários e a população e nas implicações éticas dos efeitos de suas práticas em termos jurídicos, teórico-técnicos e ideológicos.

Valendo-se desses quatro parâmetros, podese, desde o início, identificar aspectos de confluência entre os mesmos e aqueles que regem o PSF. Assim, no que se refere ao objeto e meios de trabalho, o Modelo Psicossocial propõe que fatores políticos, biopsíquicos e sócio-culturais sejam tomados como determinantes das doenças. Dessa forma, as terapias sairiam do escopo medicamentoso exclusivo, ou preponderante, e o sujeito ganharia destaque como participante principal no tratamento, sendo a família e, eventualmente, um grupo mais ampliado também incluídos como agentes fundamentais do cuidado. Na instituição, a atuação seria de natureza interprofissional, superando o formato "linha de montagem" das equipes multiprofissionais clássicas. No que tange às formas de organização da instituição, o organograma deveria ser horizontal, primando por princípios de descentralização e propostas de participação popular e dando ênfase não apenas à dimensão técnica das práticas, mas também à sua dimensão ética. As formas do relacionamento com a clientela devem priorizar o diálogo com a população, ampliando a escuta para o território mais vasto, saindo das linhas de ação apenas empreendidas pelos trabalhadores especializados. Finalmente, a concepção dos efeitos terapêuticos e éticos superaria a visão de uma terapêutica voltada apenas para a remoção de sintomas, a adaptação à realidade e a supressão de carências. Esta se fundamentaria em uma ética que valorizasse os aspectos subjetivos, além daqueles sociais e políticos da existência dos usuários.

Em linhas gerais, podem seridentificados, nas descrições acima, os princípios da integralidade da atenção e da participação social, além das propostas de ampliação do conceito de saúdedoença, da interdisciplinaridade no cuidado e da territorialização das ações, orientadores simultaneamente das ações do Modelo Psicossocial de Cuidado e do PSF 6. Pode-se propor ainda a noção de estratégia de reorganização do modelo de atenção à saúde no SUS como imagem-objetivo presente em ambos os modelos, tendo a saúde 
mental vislumbrado o Centro de Atenção Psicossocial (CAPS) como um dispositivo estratégico na conjuntura atual para a progressiva desinstitucionalização dos portadores de transtornos mentais 7 . O PSF, por sua vez, serviria como importante articulador da rede de saúde mental, no intuito de superar o modelo hospitalocêntrico, centrar o cuidado na família, e não no indivíduo doente, trabalhar com os conceitos de vigilância à saúde e no enfoque sobre o risco, desenvolver atividades que incluam a prevenção e a promoção da saúde mental e, politizando as ações de saúde de modo a lidar com os determinantes sociais do adoecimento, realizar práticas intersetoriais e desenvolver o exercício da cidadania e os mecanismos de emporwement 8 .

Na prática concreta, no entanto, esses modelos entram em conflito. De um lado, os esforços de consolidação da Política de Saúde Mental ainda têm se deparado com grandes impasses na operacionalização de uma rede de cuidados e, especialmente, da capacidade de desenvolver ações que se estendam ao espaço social mais amplo. Quanto ao PSF, além da insipiência das suas ações na área de saúde mental, aquelas existentes têm requerido uma sensibilização específica de seus profissionais, que não estão familiarizados com o universo da saúde mental, sua lógica e linguagem, o que não lhes permite levar em conta a idiossincrasia dos problemas historicamente vividos pelos portadores de transtornos mentais. Pode-se supor que um dos principais limitantes dessas ações situa-se ainda na área relativa à clínica da saúde mental.

Nesse artigo, apontaremos alguns dos nós críticos vividos pela prática da saúde mental desenvolvida por equipes do PSF, do ponto de vista de seus profissionais.

\section{A saúde mental no PSF: confluências e dissonâncias das práticas}

Os dados desse artigo foram produzidos em pesquisa intitulada A Dinâmica do Cuidado em Saúde Mental: Signos, Significados e Práticas de Profissionais no PSF e no CAPS, desenvolvida pelo Núcleo Interdisciplinar de Saúde Mental do Instituto de Saúde Coletiva da Universidade Federal da Bahia (ISC/UFBA). A presente pesquisa fundamentou-se em um modelo semiológico, pragmático e contextual que busca identificar categorias e maneiras usadas por diferentes subgrupos de pessoas para identificar, explicar e reagir a problemas de saúde mental, conformando um sistema de signos, significados e práticas 9 . Neste estudo, esses subgrupos são constituídos pelos profissionais de saúde, afastando-se da perspectiva original desse modelo de lidar com a semiologia popular 10 .

No componente que estudou o PSF, foram analisadas quatro equipes de saúde que constituíam uma unidade de saúde da família, três delas tendo um período de pelo menos dois anos de implantação na área, sendo apenas uma delas implantada há menos de um ano do momento do estudo. A etnografia do PSF realizou-se em um período de seis meses. Nesse período, foram realizados três grupos focais: um com agentes comunitários de saúde, outro com técnicos de enfermagem e auxiliar de dentista e o terceiro com profissionais de nível universitário. Foram ainda realizadas entrevistas individuais com pelo menos uma pessoa de cada categoria profissional que compõe a Equipe de Saúde da Família (ESF). Várias atividades compuseram a observação participante, tais como: visita a dois CAPS situados próximos das áreas adscritas pelas ESF estudadas, participação de visitas domiciliares com os agentes comunitários às famílias que têm pacientes com transtorno mental, participação em reuniões das equipes, visita à Feira de Saúde realizada pelas ESF, participação em grupos de relaxamento para hipertensos e diabéticos, entre outras.

Os resultados do estudo permitem traçar um perfil bastante complexo da atuação de equipes do PSF no campo da saúde mental. Neste artigo, traremos apenas aqueles aspectos que ajudam a problematizar os eixos de confluência e de dissonância entre essas práticas e as diretrizes encontradas na Política de Saúde Mental.

Um dos resultados mais significativos da pesquisa foi o fato de constatar a que ponto os profissionais se queixam da quase inexistência de práticas de saúde mental nas quatro ESF estudadas.

P: "Tem algum objetivo do PSF que você acha que não é cumprido?”.

R: “...Essa questão da saúde mental que eu não sei nem se o PSF pode estar cumprindo com esses objetivos, mas seria bom que a gente pudesse, porque a gente estaria também dando atenção aos nossos pacientes de doença mental, porque eles vêem assim a gente tratando de hipertensos, diabéticos, crianças, gestantes, mas ele não é tratado como doente mental, e talvez, como eu já tive paciente mesmo da família me procurar pra ver o que eu posso fazer, mas eu não posso fazer nada, nem a minha unidade de saúde, então, eu acho que é um objetivo que a gente não está cumprindo..." (agente comunitário de saúde).

Respostas como essa foram obtidas na maioria das entrevistas. Muitas são as razões apontadas para a não-inclusão da saúde mental enquanto campo de atuação nas equipes estudadas, fato 
que se pode dividir em quatro grupos de causas atribuídas pelos entrevistados: (i) o desconhecimento acerca da Reforma Psiquiátrica e a falta de capacitação em saúde mental dos profissionais e técnicos do PSF; (ii) a não-identificação por parte da população de problemas em saúde mental como prioridades nas áreas estudadas; (iii) a falta de condições para o atendimento desses casos no PSF, o que inclui a inexistência de medicações psiquiátricas para fornecer aos pacientes; (iv) a inexistência de uma rede em saúde mental, inclusive a falta de entrosamento com serviços de saúde mental que funcionem como retaguarda e permitam a referência rápida em caso de necessidade, entre outras.

A despeito de referirem a quase inexistência de ações de saúde mental no âmbito do PSF, quase todos os profissionais entrevistados tinham alguma situação para relatar de tratamento desses pacientes, em geral apontando para o limite desta ação. Há, no entanto, muitas tentativas, isoladas ou em grupo, mais bem sucedidas, de manejo concreto de casos de transtornos mentais.

Dentre as categorias profissionais, os agentes comunitários de saúde se destacaram pelo contato com casos de portadores de transtornos mentais, demonstrando conhecimento dessa problemática na sua realidade e referindo habilidade de identificar os mesmos, sem que, necessariamente, tenham sido capazes de oferecer uma solução adequada para o mesmo: "existe uma preocupação, mas não é algo que fica na nata do PSF, existe uma preocupação quanto se tem um doente mental, uma pessoa especial aqui na área. A gente traz à atenção durante as reuniões [de equipe], às vezes a médica vai, conversa, mas eu vejo que é muito deficiente, é quase zero o que o PSF faz pra saúde mental" (agente comunitário de saúde).

O grupo dos agentes comunitários de saúde mostra um trânsito mais cotidiano com famílias que têm algum membro com problema mental e, talvez por serem residentes na comunidade, tentam formas de lidar de modo mais contínuo com esses casos.

"Eu acompanho, porque é mais a função do ACS (...). Às vezes a médica pergunta 'Como está?', mas não volta lá pra fazer uma visita, não está ali rente com o paciente; agora eu acompanho e acredito que os colegas também acompanham ali, está atento se internou, se saiu, se fugiu..." (agente comunitário de saúde).

Entre os auxiliares de enfermagem, verificouse que há uma maior variedade de atitudes: embora alguns assumam uma atitude mais pró-ativa, outros se posicionam mais na retaguarda do tratamento, trabalhando sempre a partir da definição dos profissionais de nível superior, resis- tindo a assumir qualquer tipo de protagonismo: “...quando não é cadastrado, eu não faço nada; eu vejo e não tomo reação nenhuma. Quando é cadastrado, eu procuro saber do agente se ele pode me levar até a família, para saber se está tomando a medicação, se está freqüentando o médico e procuro o médico da equipe, se ele sabe que existe esse paciente, como éque a gente faz para poder chegar até ele" (auxiliar de enfermagem).

Com relação a profissionais de nível superior, a questão se coloca em termos de que a maior responsabilidade é atribuída ao médico. Na próxima fala, nota-se o paradoxo em que a narradora afirma que pode contar com uma equipe, mas, na realidade, busca segurança no saber-poder médico:

P: "Quando você percebe que alguém tem problema mental, que tipo de ações que você toma?”.

R: "Normalmente, eu sinalizo pro médico que, graças a Deus, tem essa questão da equipe (...) normalmente eu olho no prontuário pra ver se ele já foi atendido. Então vejo se consigo pescar alguma coisa, depois eu vou conversar com o médico, eu procuro na mesma hora, ou depois do atendimento (...): 'aquela paciente tal', e sinalizo pro agente comunitário. Aí, eu vou procurar ver se tem algum encaminhamento pra ser feito..." (odontóloga).

Segundo os profissionais, um dos aspectos fundamentais que influencia a possível inclusão de um caso entre aqueles a serem cuidados no nível da atenção básica refere-se ao diagnóstico em saúde mental. Nesse sentido, há uma diferença estabelecida entre problemas leves e problemas graves. Para os primeiros, reconhece-se uma maior freqüência na população atendida e uma possibilidade de manejo sem grande necessidade de capacitação específica. Existe mesmo uma adequação desse manejo por parte de alguns profissionais àquilo que já realizam como "clínica da promoção da qualidade de vida”, indicando uma relação que estabelecem entre os determinantes piscossociais (desemprego, precariedade da vida, violência urbana etc.) e o sofrimento mental 11. Isso demonstra que a promoção da saúde funciona como um conceito guarda-chuva que estabelece que a ação sobre fatores inespecíficos, tais quais aqueles que melhoram as condições de vida das populações, tem um impacto favorável sobre diversas formas de adoecimento humano.

"De todas as formas, independente de a gente ver saúde mental como doença psiquiátrica! Assim, agente vê saúde mental em problemas psicossociais! Pessoas que chegam ansiosas, depressivas pela questão do desemprego, da fome. E que você, de uma certa maneira, tem que ter direcionamento pra conduzir uma consulta de um paciente desse. Porque, assim, às vezes, até a gente atrapalha a questão de saúde mental e direciona pras doenças, 
as esquizofrenias e as outras coisas. (...) mas temo outro lado. Tem o lado de uma pessoa que chega, que não tem nenhum distúrbio psiquiátrico, mas que naquele momento está sofrendo de uma deficiência mental por causas externas. E ela precisa de um direcionamento que vai ter que ser diferente..." (enfermeira).

Ainda que, de uma forma geral, haja certa abertura para o tratamento de pacientes com problemas psicossociais, ou sofrimento mental mais leve, tais como depressões e ansiedades, certos profissionais médicos afirmam se sentir à vontade apenas para prescrever antidepressivos, mas não ansiolíticos, e muito menos antipsicóticos. Isso revela representações associadas a doenças diferentes e o receio que elas produzem. A depressão parece surgir como uma doença mais banalizada na sociedade contemporânea e talvez mais próxima do vivido de cada pessoa, para além de sua condição de profissional, o que adiciona uma experiência de familiaridade ao manejo da mesma. Já o uso do ansiolítico está muito relacionado ao risco de dependência química, o que produz um certo temor, "saudável" a nosso ver, nos clínicos do PSF. Quanto às psicoses, sem dúvida, são aqueles problemas que provocam maior desconforto pela construção imaginária social que a envolve e que atinge não apenas a população geral, mas também os profissionais de saúde quando da sua formação.

"Ela falou sobre os casos de pacientes com transtornos mentais que tem, diz que, em sua área, geralmente eles já passaram por uma instituição psiquiátrica, e que apenas alguns casos de depressão é que ela prescreve antidepressivo, mas não prescreve antipsicótico, porque "não gosta' preferindo encaminhar para o CAPS" (diário de campo).

Entre as práticas realizadas com pacientes portadores de transtornos mentais nas ESF estudadas, existem aquelas que podemos definir como inadequadas ou pautadas em concepções retrógradas dentro do campo da saúde mental com base em três parâmetros. O primeiro deles diz respeito a ações excessivamente normatizadoras e apoiadas no modelo biomédico hospitalocêntrico. O segundo destaca ações de cunho discriminatório e o terceiro, aquelas de caráter moralista-repressivo.

Um dos técnicos de enfermagem descreve o tipo de ação que ocorre na prática do PSF. Pelo relato, observa-se que existe uma tentativa de manejo de alguns casos apoiada em formas muito biomédicas e tradicionais de compreensão da doença mental, pautadas na medicamentação, na normatividade dos comportamentos, na expectativa de comportamentos agressivos e na internação como horizonte terapêutico.
“...Os médicos mesmo do PSF têm paciente que tem o problema mental (...) a gente tenta trabalhar com eles, vê o que eles precisam, medicações, vê se ele vai precisar internar, é um trabalho em grupo, como que vai chegar até ele (...). Às vezes o médico orienta o agente a como se deve lidar com ele, se tá tomando o remédio, ele visita, vai na casa, procura indagar da família, da mãe se tá tomando remédio, faz tipo uma entrevista" (auxiliar de enfermagem).

Outro aspecto importante referido é a discriminação que se observa por parte de certos profissionais em relação ao cuidado com o portador de transtorno mental. Aponta-se que essa discriminação pode-se manifestar sob a forma de uma recusa de tratamento físico, e não psíquico.

P: “Discriminação por parte de quem?".

R: "De todos! (...) Não tô falando que eles maltratem, mas, quando a gente chega, a gente sente que dá aquela parada! 'Doente mental? É aqui mesmo?!' (...) na época, minha irmã estava com um dente doendo, aí eu falei que ia trazer minha irmã; o dentista não aceitou. Disse que tinha que procurar um dentista que tratasse desse problema. Quer dizer, ela não pode porque é doente mental, ele não tem capacidade de atender um doente mental..." (agente comunitário de saúde).

Essa inadequação no manejo de situações concretas pode manifestar-se ainda em incidentes que envolvem pessoas com comportamentos que se distanciam da "normalidade" esperada.

"Não quer abrir a boca, fica com o olho assim [mostra a expressão do olho] vai fazer o quê? (...) eu não sou paciente: quando eu vejo o bicho pegar, eu saio correndo. Já C. [o dentista] tenta conversar e tira a roupa toda [o guarda-pó e a máscara]. 'Você tá me vendo aqui? Eu sou C.! Não vou fazer mal, não!' Essa menina mesmo morre de medo, não pode ver, quando ela vê todo de branco, ela não entra na sala..." (grupo focal de técnicos).

No último relato, observa-se que, enquanto o dentista tenta reduzir a ansiedade do paciente, a técnica demonstra medo e impaciência para lidar com o episódio. Observa-se, portanto, que ainda é muito freqüente o recurso a atitudes moralizantes e repressivas quando não se sabe como lidar com a situação, ou quando não se dispõe de ações comunitárias para enfrentar, ou pelo menos refletir sobre problemas como o alcoolismo, o nervoso, as reações exacerbadas de medo etc.

\section{A lógica de inclusão da saúde mental através da lógica do PSF}

Uma das evidências mais interessantes da pesquisa aponta para as tentativas realizadas por muitos dos profissionais entrevistados de pro- 
duzir sínteses espontâneas entre a lógica de funcionamento e de concepção do PSF e a lógica da inclusão da saúde mental no mesmo.

A primeira dessas sínteses situa-se no campo da integralidade da assistência. Embora insipiente, percebe-se uma busca por parte de alguns profissionais em reduzir a distância existente entre problemas da mente e problemas do corpo. Constroem-se dois tipos de argumento nessa direção: o primeiro, mais largamente aceito, é o da semelhança entre os vários tipos de doença pela sua causalidade psicossocial, que tanto pode gerar uma doença hipertensiva quanto um processo de enlouquecimento; o segundo argumento dirige-se à necessidade de se reagir socialmente a todo tipo de doença da mesma forma, evitando tratar os doentes mentais de uma forma discriminatória. Fala-se então da compartimentalização do cuidado no PSF, tratando as doenças físicas dos pacientes, sem que se ocupe da parte mental.

“...Ninguém discrimina outro, porque é hipertenso, é diabético; mas discrimina se for doente mental" (agente comunitário de saúde).

"Eu acho que é uma preocupação como outra, mas a gente não visualiza como um grupo a intervir, como a gente tem grupos específicos que tem de preencher papel. Eu vejo como uma doença como outra, uma pessoa vem aqui com uma úlcera, uma pessoa vem aqui com depressão, com distúrbio mental, (...) pelo menos a minha equipe, não sei as outras, a gente não tem um trabalho específico com a saúde mental, e o PSF trabalha muito com isso, com grupo, com risco, com esses termos de planejamento" (médica).

A despeito do estreitamento dessa relação mente/corpo no discurso indicar certa mudança na visão de mundo associada ao processo saúde-doença-cuidados, no campo das práticas, a fragmentação ainda parece muito presente. Nessa última narrativa, há um reconhecimento da ausência de recursos operacionais e teóricos no PSF para lidar com a saúde mental, de modo inclusive a que esta última venha a se beneficiar dos avanços técnico-metodológicos que esse programa vem alcançando. Em linhas gerais, o que chama, sobretudo, a atenção, conforme é indicado por vários profissionais, é a inexistência de uma "estratégia" no âmbito do PSF para lidar com a saúde mental, uma estratégia que contemple ações de promoção, de comunicação e educação em saúde, de práticas coletivas, além das individuais.

“...Que serviços a equipe do PSF oferece aos portadores de transtorno psíquicos, no momento, é que são quatro equipes de saúde, a minha equipe? (...) Eu acho que nada, além do atendimento que a gente faz no consultório normal, as orienta- ções habituais, a referência, quando não está no nosso nível de competência, nos casos mais complicados. Por enquanto não temos uma estratégia bolada para lidar com esses casos" (médico).

A consciência de um valor maior das "abordagens coletivas” surge como um aspecto curioso que indica uma transformação nas concepções e práticas desses profissionais, fortemente influenciadas por novas formações encampadas pelo, e posições ideológicas do campo da saúde coletiva. Há uma importante convergência entre essa perspectiva e aquela que está sendo progressivamente adotada nos novos dispositivos da rede da saúde mental, em que também se enfatizam as práticas grupais e o conhecimento dos pacientes para além da sua individualidade, contextualizando-os no seu grupo social mais amplo ${ }^{12}$. Esses aspectos associam-se à valorização das práticas políticas e associativas que melhor conduzem a uma consciência sanitária mais alargada, além de entenderem que o grupo apresenta um aporte terapêutico de outra natureza ${ }^{13}$. Aproxima-se ainda de uma leitura menos individualizada da realidade médica, tanto na gênese quanto na solução para as doenças. $\mathrm{O}$ valor do coletivo pode então ser destacado como uma das grandes medidas de transformação das práticas de saúde influenciadas pelo ideário da medicina social.

Nessa perspectiva os pontos de confluência deste com os ideais presentes em um dos movimentos que inspiraram fortemente a Reforma Psiquiátrica Brasileira são muito grandes. Foi com o Movimento da Psiquiatria Democrática Italiana que a noção que cerca a atuação em saúde mental no território ganha contornos mais politizados e com uma ênfase no aspecto psicossocial do adoecimento e do seu cuidado 14,15. Fundamenta-se em uma intenção de desconstrução progressiva de toda instituição ou prática de caráter manicomial e excludente das pessoas portadoras de transtorno mental, desenvolvendo-se estratégias sociais, políticas e culturais que assegurem ao louco um lugar de cidadão. $\mathrm{O}$ território ganha centralidade nesse movimento, pois a idéia forte situa-se em que os portadores de transtornos mentais habitem mais e mais os espaços da comunidade, saindo dos espaços de reclusão e de marginalização real e simbólica. O território é compreendido como espaço geográfico habitado, instituído de significados, afeto, o espaço de laços sociais e de garantia de qualidade de vida, de manutenção econômica e de exercício político dos cidadãos 16 .

O manejo do território na perspectiva do cuidado ao portador de transtorno mental, o que inclui a incorporação das relações e dinâmicas sociais que aí se realizam, pressupõe o desen- 
volvimento de novas tecnologias que questionam uma clínica tradicionalmente pautada no indivíduo e que, muitas vezes, negligenciou os aspectos sociais e políticos das experiências dos sujeitos. Esse mesmo tipo de reflexão tem orientado muitas das proposições e reorientações do modelo de atenção à saúde como um todo, o que inclui o PSF. Isso não significa que haja modelos uniformizados a seguir, particularmente tendo em conta os caminhos já percorridos por cada campo disciplinar e as necessidades específicas dos indivíduos para os quais cada tipo de cuidado é oferecido.

Por conseguinte, percebe-se que a área de saúde mental, pela sua própria especificidade, desenvolveu teorias, métodos e técnicas de compreensão e de abordagem do sujeito, especialmente dos fenômenos da ordem da alteridade raramente incorporados pelas demais clínicas. Ao contrário, a estigmatização que recaiu sobre os portadores de transtornos mentais contou com o reforço freqüente de profissionais de saúde de outras áreas disciplinares. Isso ficou visível no exílio vivido pelo campo da saúde mental nas instituições de saúde, cujo exemplo paradigmático foi a construção de hospitais e ambulatórios psiquiátricos separados dos hospitais e ambulatórios gerais.

A dicotomia mente/corpo, legitimada e reforçada historicamente, e que ainda hoje organiza concepções e práticas, associada aos valores que desqualificaram e excluíram os portadores de doenças mentais do convívio social produziram fortes enraizamentos no imaginário coletivo, inclusive o dos cuidadores da saúde 17. É inegável que há muitos esforços de desconstruir esses paradigmas, fato que se verifica pela ênfase recente atribuída ao papel do sujeito e pela atual valorização das "tecnologias leves" $18 \mathrm{em}$ vários campos disciplinares. Há riscos, inclusive, de que essa ênfase à emergência do sujeito seja capturada em um excesso de psicologismo que confunde níveis distintos de compreensão da realidade. Esse aspecto vem sendo objeto de debate no próprio campo de saúde mental quando se refere ao conceito de uma clínica ampliada que se interroga sobre de que sujeito se está falando e que tenta ultrapassar a polaridade sujeito/sociedade 4,7,19, reconhecendo que, além de um sujeito do inconsciente, é preciso se tratar do ser de necessidades, muitas vezes situado em condições excludentes e de baixo poder de contratualidade 20 .

Tomando em conta esses riscos reducionistas, no entanto, o problema maior a ser enfrentado situa-se na capacidade que as instituições de ensino e outras venham a ter na formação adequada de profissionais que terão o papel cada vez maior no cuidado aos portadores de transtornos mentais, tendo em vista a conjuntura atual de não-hospitalização progressiva. Isso não implica exigir dos mesmos a substituição dos especialistas, tendo em conta o seu escopo de ação universalista e generalista, mas em muni-los com recursos capazes de torná-los reais colaboradores, artífices atuando em outro ponto da rede, em outro nível de complexidade. Enfrentar seriamente esse desafio é encarar uma realidade presente e produtora de conseqüências práticas. O que escutamos dos nossos entrevistados é que eles já lidam no seu cotidiano com portadores de sofrimento/transtorno mental. Ademais, existe uma manifestação do desejo de se qualificarem para esse tipo de manejo por duas razões igualmente importantes: pelo sentimento de estarem descumprindo a ética do cuidar ao não saberem como o fazer, ou pela angústia provocada ao defrontar-se com situações humanamente e afetivamente exigentes, como freqüentemente o são problemas dessa natureza. A maioria desses profissionais se sente despreparado para o manejo com pessoas portadoras de transtornos mentais, o que gera sentimentos de impotência e frustração.

"Aqui já teve caso da gente internar, acompanhar, nada. A gente tem um caso, são dois pacientes que a gente orienta se tá, e eles nunca chegou a precisar, única coisa que já aconteceu foi o policial levar ele até em casa, que ele estava agredindo, $e$ a mãe pediu para ele tomar a medicação. Conseguimos contornar esse caso, tomou a medicação, ficou calmo. Mas, se esse paciente vier a ter alguma crise e precisar do auxílio da equipe do PSF, eu, como técnico, não sei te dizer como fazer" (agente comunitário de saúde).

Nas entrevistas realizadas, muitos dos trabalhadores criticaram os cursos rápidos aos quais tiveram acesso e que, segundo eles, não preparam efetivamente para o manejo desse tipo de paciente.

"Falta preparo de nossa parte, um certo preparo técnico, eu acho que deveria haver alguma atualização pra gente em saúde mental, não esse curso que a gente fez no ano passado (...) passageiro, uma semana de curso, naquela metodologia expositiva, que não é muito eficiente. (...) não foi uma coisa que fixou muito na mente. Cada profissional aqui tem sua experiência em saúde mental, pode ser que uns tenham mais facilidade que outros, (...) já que pedem que a gente atenda de forma integral a comunidade na área de saúde, deveriam nos capacitar melhor nessa área de saúde mental" (médico).

Evidentemente, não se pode idealizar essa demanda, sabendo-se das resistências que também envolvem esse cuidado e que mobilizam justifi- 
cativas que vão desde o excesso de trabalho dos profissionais da rede básica para ainda se ocuparem de mais um problema, até questões inconscientes que incluem aspectos pessoais. Sabe-se, por exemplo, que cursos são oferecidos sem que a adesão seja necessariamente tão expressiva. A despeito dessas dificuldades, as estratégias para alcançar esse público, de forma competente e responsável, são imprescindíveis. Nesse momento de reorientação do modelo de atenção em saúde mental, com importantes conquistas legais e com a ampliação crescente do debate que cerca a saúde mental, estimulada, sobretudo, pela descentralização e municipalização do seu cuidado, devem ser multiplicados esforços na direção de uma real transformação cultural da mentalidade e das práticas profissionais nesse campo do saber. Atender essa demanda de capacitação dos profissionais da atenção básica exigiria uma atuação em duas dimensões do modelo, tais que propostas por Amarante 4: a dimensão técnico-assistencial e a dimensão epistemológica com vias a alcançar o campo sócio-cultural mais vasto.

No rastro desse modelo, situa-se uma rara experiência, e de rara riqueza, desenvolvida por uma equipe de saúde mental que tentou materializar capacitação e intervenção no nível do PSF, movidos por uma profunda consciência desse espaço de atuação, suas especificidades e necessidades. Trata-se do Projeto Qualis, coordenado por Antonio Lancetti 21 e desenvolvido na cidade de São Paulo. Muito dessa experiência está descrito na obra citada, mas alguns aspectos merecem destaque. O primeiro deles foi a tentativa de produzir com a equipe de saúde da família uma troca verdadeira, com a produção de saberes e práticas que partiam da realidade de atuação daqueles profissionais. Em segundo lugar, a equipe de saúde mental se colocava em uma condição itinerante ("volante"), promotora de experiências de autonomia responsável, e não de laços de dependência. Em terceiro lugar, havia uma determinação de explorar a fundo propósitos como a integralidade da assistência, o aumento da resolutividade das ações nesse nível da atenção, a responsabilização dos profissionais por aqueles que necessitavam de seu cuidado, a coletivização das ações de saúde, entre outros. Por fim, chama a atenção a ênfase dada sobre o que podemos chamar de uma pedagogia libertária e emancipatória 22, que ousa romper com idéias pré-concebidas e situar-se na lógica da inventividade.

Esse seria apenas um exemplo orientado na direção do horizonte das profícuas possibilidades que se descortinam nesse encontro de níveis de cuidado, ou mais acertadamente, de sujeitos cuidadores, no enfrentamento de importantes desafios colocados pelo campo da saúde mental.

\section{Resumo}

Em um grande número de Reformas Psiquiátricas que se sedimentam sobre os pressupostos básicos da nãoinstitucionalização dos pacientes psiquiátricos e da consolidação de bases territoriais do cuidado em saúde mental, a ênfase é atribuída a uma rede de cuidados que contemple a rede de atenção primária. No Brasil, a Reforma Psiquiátrica Brasileira nasce no bojo da Reforma Sanitária, guardando em comum princípios que reorientariam o modelo de atenção. Neste artigo, discutiremos as articulações entre esses dois movimentos por intermédio das práticas concretas do cuidado de saúde mental no Programa Saúde da Família (PSF), tomando como base um estudo etnográfico com quatro equipes de saúde da família, em que priorizamos a narrativa dos trabalhadores de saúde. Analisaremos, dessas práticas, discrepâncias entre o proposto normativo e o instituído, fatores dificultadores e conquistas da operacionalização das ações e limites da confrontação e potencialidades da transversalidade de campos epistemológicos particulares como a clínica ampliada da saúde mental e do PSF. Moveremos nossa discussão com base em conceitos como modelo psicossocial do cuidado, integralidade da atenção, participação social, territorialidade, ações coletivas, entre outros.

Saúde Mental; Programa Saúde da Família; Atenção Primária à Saúde 


\section{Colaboradores}

M. Nunes coordenou a pesquisa e redigiu o texto junto com V. J. Jucá. Ambas participaram da coleta e análise dos dados da pesquisa. C. P. B. Valentim participou da coleta e análise dos dados e revisão do artigo.

\section{Referências}

1. World Health Organization. Organization of mental health services in developing countries. Sixteen report of WHO Expert Committee on Mental Health. Geneva: World Health Organization; 1975. (WHO Technical Report Series, 564).

2. World Health Organization. Mental health care in developing countries: a critical appraisal of research findings. Geneva: World Health Organization; 1984. (WHO Technical Report Series, 698).

3. Torrenté M. Ressources alternatives en santé mentale [Dissertação de Mestrado]. Montreal: Département d'Anthropologie, Université de Montreal; 1995.

4. Amarante P. A (clínica) e a Reforma Psiquiátrica. In: Amarante P, coordenador. Archivos de saúde mental e atenção psicossocial. Rio de Janeiro: Nau Editora; 2003. p. 45-66.

5. Costa-Rosa A. O modo psicossocial: um paradigma das práticas substitutivas ao modo asilar. In: Amarante P, organizador. Ensaios, subjetividade, saúde mental, sociedade. Rio de Janeiro: Editora Fiocruz; 2000. p. 141-68.

6. Ministério da Saúde. Saúde da família: uma estratégia para reorientação do modelo assistencial. 2a Ed. Brasília: Ministério da Saúde; 1998.

7. Tenório F. A psicanálise e a clínica da reforma psiquiátrica. Rio de Janeiro: Rios Ambiciosos; 2001.

8. Paim JS. Saúde da família: espaço de reflexão e contra-hegemonia. Interface Comun Saúde Educ 2001; 5:143-6.

9. Corin E, Bibeau G, Martin JM, Laplante R. Comprendre pour soigner autrement: Repères pour régionaliser les services de santé mentale. Montréal: Presses de l'Université de Montréal; 1990. 
10. Corin E, Bibeau G, Uchoâ E. Eléments d'une sémiologie anthropologique des troubles psychiques chez les Bambara, Soninké et Bwa du Mali. Anthropol Soc 1993; 17:125-56.

11. Pitta AMF. Qualidade de vida de clientes de serviços de saúde mental. Rev Psiquiatr Clín (São Paulo) 1999; 26:68-77.

12. Teixeira CF. Saúde da família, promoção e vigilância: construindo a integralidade da atenção à saúde no SUS. Revista Brasileira de Saúde da Família 2004; 7:10-23.

13. Wallerstein N, Bernstein E. Introduction to community empowerment participatory education and health. Health Educ Q 1994; 21:141-8

14. Desviat M. A reforma psiquiátrica. Rio de Janeiro: Editora Fiocruz; 1999.

15. Rotelli F, De Leonardis O, Mauri D. Desinstitucionalização. 2a Ed. São Paulo: Editora Hucitec; 2001.

16. Delgado PG. A psiquiatria no território: construindo uma rede de atenção psicossocial. Saúde em Foco: Informe Epidemiológico em Saúde Coletiva 1997; 16:41-3.
18. Rodrigues CR, Figueiredo MAC. Concepções sobre a doença mental em profissionais, usuários e seus familiares. Estud Psicol (Natal) 2003; 8:117-25.

19. Merhy EE. Saúde: a cartografia do trabalho vivo. São Paulo: Editora Hucitec; 2002.

20. Bezerra JRB. A clínica e a reabilitação psicossocial. In: Pitta A, organizador. Reabilitação psicossocial no Brasil. 2a Ed. São Paulo: Editora Hucitec; 2001. p. 137-42.

21. Tykanori R. Contratualidade e reabilitação psicossocial. In: Pitta A, organizador. Reabilitação psicossocial no Brasil. 2a Ed. São Paulo: Editora Hucitec; 2001. p. 55-9.

22. Lancetti A. Saúde mental nas entranhas da metrópole. In: Lancetti A, organizador. Saúde mental e saúde da família. 2a Ed. São Paulo: Editora Hucitec; 2001. p. 11-52. (Saúde e Loucura, 7).

23. Freire P. Educação como prática da liberdade. 26a Ed. Rio de Janeiro: Editora Paz e Terra; 2002.

Recebido em 02/Mai/2006

Versão final reapresentada em 21/Fev/2007

Aprovado em 04/Abr/2007 